\title{
Biodiversity and climate change perceptions in arid lands- implications for sustainable development in Botswana
}

\author{
J.R. Atlhopheng ${ }^{1}$, M.G. Moshoeshoe ${ }^{2}$, G. Phunyuka ${ }^{2}$ and W. Mokgopa ${ }^{2}$ \\ ${ }^{1}$ Department of Environmental Science, University of Botswana, Gaborone, Botswana \\ ${ }^{2}$ Department of Forestry and Range Resources
}

\section{ARTICLE INFORMATION}

\section{Keywords}

Climate change

Biodiversity values

Sustainable development,

Perception audit

Botswana

Article History:
$\begin{array}{ll}\text { Submission date: } & \text { 01 Aug. } 2018 \\ \text { Revised: } & \text { 14 Jun. } 2019 \\ \text { Accepted: } & \text { 12 Jul. } 2019 \\ \text { Available online: } & \text { 24 Sept. } 2019 \\ \text { https://bojaas.buan.ac.bw }\end{array}$

\section{Corresponding Author:}

Julius R. Atlhopheng

용 : (+267) 3552471

兽 : (+267) 3185097

四: atlhophe@mopipi.ub.bw
Abstract: The paper considers the biodiversity and climate change perceptions in the semi-arid landscape of Botswana. Ecosystem services are essential to the planet's equilibrium/wellbeing. However, anthropogenic influences, including climate change remain a stressor to the biodiversity resources. For Botswana, the land degradation and droughts, climate change and livelihoods are intertwined to divulge distinctive vulnerabilities and impacts. The existing action plans such as National Biodiversity Strategy and Action Plan (NBSAP), the Botswana National Action Programme to Combat Desertification (BNAP-CCD) and climate change's nationally determined contributions (NDCs) point to the need for synergies. Research projects highlight increased vulnerabilities for various sectors, which challenge the country's sustainability initiatives to meet the Sustainable Development Goals (SDGs), National Development Plan 11 (NDP11) and the Vision 2036 imperatives. The perception study reveals the general public's interpretations of what is good and what are challenges, at district levels. These reveal that biodiversity or climate change are not perceived to contribute much to the 'good' of the country, except for 2 district groups in northern Botswana. The national challenges hinge much on biodiversity loss and climate change - hence restricting attainment of the national development priorities.

\section{Introduction}

The biodiversity is important to livelihoods i.e. utilization for livelihoods and enhancing economic opportunities. The resources need to be transformed and protected. Hence a need for conservation of biodiversity, sustainable utilization and ensuring fair $\&$ equitable sharing of benefits from genetic resources. To achieve these, there is a need for using appropriate knowledge systems i.e. Traditional knowledge systems are important in countries that host the genetic resources, as well as use of modern scientific knowledge. This study, through perception audits involving diversity of stakeholders i.e. communities, policy makers and researchers aims to blend the knowledge systems, as output. Research is important to inform innovations so as to transform the resources we have. Researchers thus need to take up these challenges, hence this study.
The country has undergone shifts across time, with settlements and livelihoods affecting the former wildlife biodiversity in some parts of Boteti (Cashdan, 1986) with the wildlife declines ascribed to competition with livestock. Further, noting that the degradation had been severe much earlier e.g. 1934 reports; yet some attributed overhunting to have reduced wildlife. Thus human influences included competition of cattle with wildlife as well as habitat destruction which included arable fields. Mayaud et al (2017) hint to landscape changes due to climate change in the Kalahari, even though limited (Ashkenazy et al 2012). Mayaud et al (2017) indicated that land management strategies would be key to reduce impacts e.g. 'large, abrupt and irreversible' shifts may lead to loss of 'bioproductivity and biodiversity'. Reed et al (2015) provided payment of ecosystem services (PES) as a solution for Kalahari land management. Fire is 
indicated as a stressor in drylands (Mayaud et al (2017); NBSAP (2016)). The climate has shifted across geological time, based on the Lake Ngami pollen analysis, producing varying ecosystems (Cordova et al 2017). Keller et al (2017) on Southern Africa drylands, highlighted ecosystem services contribution e.g. to poverty alleviation - that 'provisioning services' (e.g. natural products, fodder, water) are used by poor households for income generation (10-50\% of household income). These build safety nets/insurances during extremes or shocks. The regulating services contribute to protection e.g. drainage basins, soil fertility management; while cultural services remain important to local cultures as well as community tourism ventures. The supporting services are instrumental in ecotourism - hence conservation important to protect the natural resources, which avail ecosystem based adaptation against climate change and offer payment of ecosystem services (guarding against ecosystem misuse). These emphasise the resilience and adaptability needs. Keller et al (2017) noted with concern that some biodiversity elements which are targeted, by international poachers deprive the poor from potential income benefits.

The Community Based Natural Resources Management policy of 2007 - noted that communities have an interest in sustainable management and utilization of natural resources in their environs, that they absorb costs associated with conservation of their local natural resources; as well as having the best knowledge about the intrinsic value of the resources. That for meaningful engagement of communities, the benefits must outweigh the costs of conservation. To this end, investment in natural resources may be entrepreneurial in certain locales, with inclusion assured i.e. equitable sharing of benefits for the community.

The Botswana (NBSAP) National Biodiversity Strategy and Action Plan (2016) notes the key role of biodiversity in eradicating poverty and that it is underpinned under sustainable development and other international exigencies. The biosafety concerns in the Cartagena protocol i.e. avoidance of genetic pollution and genetically modified organisms to ensure sustainable use of biodiversity; and the Nagoya protocol on ensuring access and benefit sharing of biodiversity resources. The NBSAP offers synergies with other Rio conventions e.g. carbon sequestration for climate change mitigation and vegetation protection to curb land degradation. Thus ecosystem integrity would ensue across ecoregions resulting in climate change mitigation and combating of land degradation.
In Vision 2036, the role of biodiversity as economic resources, provision of ecosystem services and in enhancing community resilience to climate change and degradation- are noted. Thus research and traditional knowledge systems would ensure sustainable benefits from biodiversity.

Climate change mitigation (reductions in emissions) and adaptation (to impacts of climate change) have been outlined in the Nationally Determined Contributions (2016) made to the UNFCCC. Botswana intends to reduce emissions (mitigation) of $\mathrm{CO}_{2}, \mathrm{~N}_{2} \mathrm{O}, \mathrm{CH}_{4}$ for the sectors on energy (mobile and stationery sources) waste and agriculture. Botswana would adopt the Intergovernmental Panel on Climate Change (IPCC) methods as well as market mechanisms to achieve the UNFCCC obligations. For agriculture, this will include adoption of Climate Smart Agriculture, planting various crops to enhance chances of success, to maintain soil carbon as well as to reduce soil erosion. For livestock, the focus is on reducing emissions from enteric fermentation. As for infrastructure development, the mitigation strategy during NDP11 is for projects to be eco-friendly. Climate change adaptation priorities include Sustainable Land Management (SLM), National Water Master Plans, Agriculture and Health. SLM initiatives enhance resiliencies and reduce the vulnerability of communities to climate change. SLM thus offers multiple benefits for biodiversity, land degradation and climate change - hence synergies across the three Rio Conventions (UNCBD, UNCCD \& UNFCCC).

Agriculture is key to food security and nutrition for the national population. It is equally important for poverty eradication; to ensure survival of various biodiversity assets including livestock - whose sustenance is important to the national economy and social fabric. To enhance food security, technological interventions include minimal tillage, drought resistant crops, fast maturing varieties, supplementary feeding and development/adoption of drought tolerant livestock breeds- to adapt to a changing climate. During NDP10, the sector experienced infrastructure challenges e.g. roads, water, markets; diseases and pests affecting economically important assets. The prevailing silo planning limited the reaping of multiple benefits e.g. between agriculture and transport, for instance.

Health and other sectors experience the impacts and vulnerabilities e.g. epidemics that occur for abnormally high rainfall years which may lead to diarrhea etc. Thus proper adaptation benefits from; availability of climate change information (research), national policies across various sectors, national development indicators and frameworks/initiatives. 
The NDP11 considers sustainable development to imbibe "expanding the economic base without unduly sacrificing its environment," page 146 of NDP11 i.e. meeting the needs of the present and future generations, sustainably. The NDP11 (clause 6.170) new strategic focus aims to utilize research, as a vehicle for sustainable development. One of the key deliverables is strengthening research and innovation capacity. In addition, technologies would be adapted to local conditions, to ensure achievement of high priority sustainable development needs. Partnerships are key, in unravelling multidimensional issues across sectors from local to international levels. Indigenous knowledge, for the production of goods and services, remains one of the potential sources of sustainable development e.g. to diversify livelihoods. Development strategies e.g. tourism in a climate change reality (Hambira, 2017) needs interventions e.g. policy choices that take into account limited knowledge on the subject, policies also being sensitive to uncertainties/risks associated with climate change.

Currently, the sustainability discourse faces some challenges on biodiversity, such as humanwildlife conflicts, poaching, water scarcity for wildlife hence need to develop water points in wildlife areas. Limited strategic planning of infrastructure has led to poor waste management, eco-unfriendly infrastructure, illegal mining and biodiversity losses. Even though CBA (cost benefit analysis) was done for infrastructure development, this was inadequate for environmental and socioeconomic impacts (NDP11 - chapter 7). In addition, the economic analysis failed to include ecosystem services' contribution to the national economy, as natural capital. Infrastructure impacts include increased carbon footprints and pollution. In NDP11, there is thus need to improve inventories e.g. biodiversity (status/diversity of species) and more public education. The Windhoek Declaration on drought in Africa, has one of its recommendations pointing to catalyzing for more resources to cover droughts, disasters and other emergencies and this to be built into the Land Degradation Neutrality Fund. This may be covered under the UNCCD national initiatives.

This paper aims to elucidate the following objectives, based on the Botswana study:

1. To study if the intrinsic values and ecosystem services are perceived to add to the 'good' of Botswana.

2. To investigate the public perception across Botswana districts, on biodiversity and climate change challenges.

3. To make recommendations for biodiversity and climate change contribution to sustainable development, based on the above.

\section{Methods and data analysis}

A focus group discussion was conducted across Botswana, to understand what they consider to be 'good' and 'challenges' - listing only the top five issues under each. This was to understand the local interpretations of what they consider good nationally. The focus group discussion has the advantage that it follows the traditional forum of resolving issues and building consensus i.e. the 'kgotla' system. The study was done under the ambit of the alignment of the National Action Programme of the UNCCD in Botswana, to align it to the 2030 agenda and prevailing national priorities. This perception study clustered some districts due to time and financial constraints. The results were subjected to thematic analysis, to unravel the key issues.

The districts were: Kgatleng and Central; North East and Chobe; North West District (Ngamiland); Southern, Kgalagadi, Kweneng, Ghanzi and South East; and finally the Gaborone region (capital city with international organisations). In addition to the above, one sub-district was engaged i.e. the Mahalapye sub-district, whose results are included. The participants came from varying government ministries, community based organisations, nongovernmental organisations, private sector, youth, elderly and politicians.

Through facilitation, the questions were asked as follows: What is good about Botswana - and why? The stakeholders were asked to list 5 key issues, they agreed upon as a group. The second question sought the perceived challenges - and why they are perceived so.

\section{Results and discussions}

The perceived 'good' about Botswana in terms of biodiversity and climate change

The results of the study present varying views from across the districts, to investigate whether biodiversity and climate change issues are seen as either contributing to the 'good' Botswana or are more of Botswana's 'challenges'. Only two districts groups (Table 1) - North West (Ngamiland) and Chobe \& North East projected biodiversity issues, as 'good'.

The biodiversity (available natural resources in abundance) provide social and economic benefits to communities (Table 2).

What is good at the sub-district level - the case of Mahalapye region

At the Mahalapye sub-district level, their view of their district (Central) is that, it has pronounced biodiversity resources e.g. big rivers with water, good rains and water points. In addition, the grazing resources are seen as good; as well as generally good 
Atlhopheng J.R. (2019). Bots. J. Agric. Appl. Sci. 13 (Issue 2 - Special): 24-31. ISSN 2661-9008

Table 1: What is good about Botswana and why - biodiversity and climate change parameters

\begin{tabular}{|c|c|c|}
\hline District & $\begin{array}{l}\text { The 'good' about Botswana on } \\
\text { biodiversity and climate change }\end{array}$ & Why good \\
\hline $\begin{array}{l}\text { Chobe and North } \\
\text { East }\end{array}$ & $\begin{array}{l}\text { Available/abundant natural } \\
\text { resources }\end{array}$ & $\begin{array}{l}\text { Income generation, tourism, natural resources } \\
\text { store history, equitable distribution of proceeds } \\
\text { from benefits, natural beauty (aesthetic value), } \\
\text { protect the natural environment. }\end{array}$ \\
\hline $\begin{array}{l}\text { North West District } \\
\text { (Ngamiland) }\end{array}$ & $\begin{array}{l}\text { Available/abundant natural } \\
\text { resources }\end{array}$ & $\begin{array}{l}\text { Attract tourism and venture investments. } \\
\text { Develop and diversify livelihoods of Batswana. }\end{array}$ \\
\hline $\begin{array}{l}\text { Mahalapye sub- } \\
\text { district }\end{array}$ & We protect our natural resources & $\begin{array}{l}\text {-Governance of natural resources done locally. } \\
\text {-Knowledge base to develop or come up with } \\
\text { our interventions/solutions. } \\
\text {-Preserves culture and ensures cross- } \\
\text { generational inheritance. } \\
\text {-Databank (nature as storage) for the future is } \\
\text { protected. }\end{array}$ \\
\hline
\end{tabular}

Table 2: The socio-economic benefits that arise from biodiversity resources

\begin{tabular}{|l|l|l|}
\hline Name of District & Social Benefits & Economic Benefits \\
\hline Chobe and North East & Natural beauty; databank; protection. & $\begin{array}{l}\text { Income generation; equitable } \\
\text { distribution of proceeds; tourism. }\end{array}$ \\
\hline Ngamiland (North West) & Develop/diversify livelihoods. & Tourism; venture investments \\
\hline Mahalapye (sub-district) & $\begin{array}{l}\text { Governance; benefits from knowledge } \\
\text { system; culture \& inheritance; databank. }\end{array}$ & N/A. \\
\hline
\end{tabular}

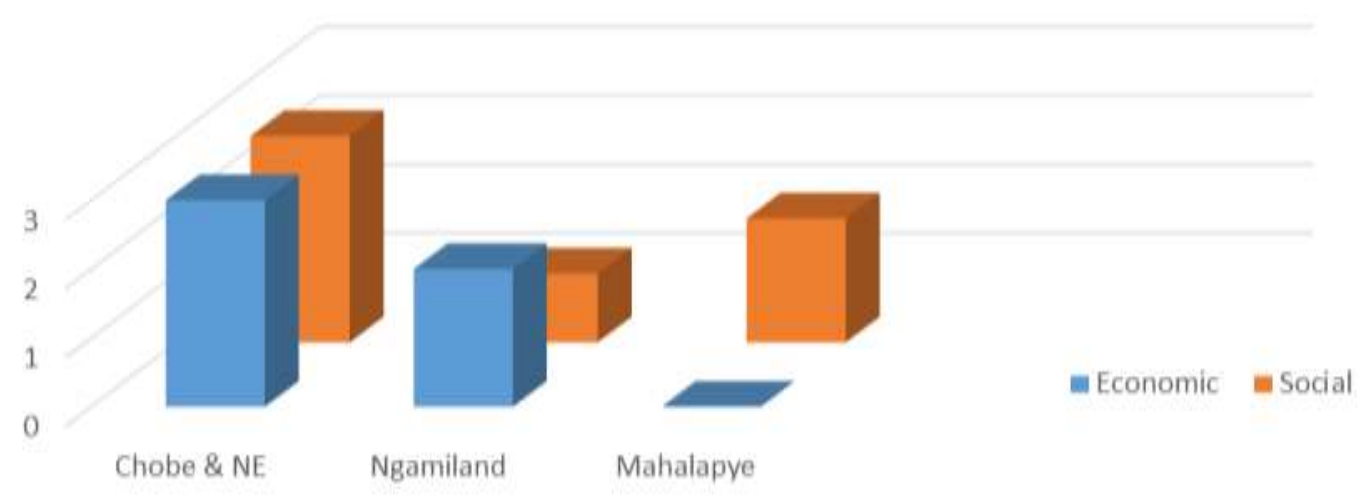

Fig. 1: The socio-economic benefits of biodiversity in Botswana

soils for seasonal land productivity following the seasonal rains (Table 2). Only two districts groups (Table 1) - North West (Ngamiland) and Chobe \& North East projected biodiversity issues, as 'good'.

The biodiversity (available natural resources in abundance) provide social and economic benefits to communities (Table 2).

What is good at the sub-district level - the case of Mahalapye region
At the Mahalapye sub-district level, their view of their district (Central) is that, it has pronounced biodiversity resources e.g. big rivers with water, good rains and water points. In addition, the grazing resources are seen as good; as well as generally good soils for seasonal land productivity following the seasonal rains (Table 2).

The biodiversity and climate change challenges across the districts in Botswana 
Atlhopheng J.R. (2019). Bots. J. Agric. Appl. Sci. 13 (Issue 2 - Special): 24-31. ISSN 2661-9008

Table 3: The districts' biodiversity/climate change challenges

\begin{tabular}{|c|c|c|}
\hline District & $\begin{array}{l}\text { The challenges about Botswana on } \\
\text { biodiversity and climate change }\end{array}$ & Why are these challenges \\
\hline $\begin{array}{l}\text { Kgatleng and } \\
\text { Central }\end{array}$ & $\begin{array}{l}\text { i. Shortage of Water } \\
\text { ii. Overgrazing/desiccations } \\
\text { iii. Drought }\end{array}$ & $\begin{array}{l}\text { Impacts of water shortages } \\
\text { - } \quad \text { Rainfall patterns altered, weather systems have } \\
\text { changed (climate change). Extreme/destructive } \\
\text { rainfall types as the norm. } \\
\text { - } \quad \text { Less rainfall, does not lead to river flows. } \\
\text { - } \quad \text { Limited capacity and technology to provide } \\
\text { communities with water. } \\
\text { - } \quad \text { We live in a dry land. } \\
\text { Overgrazing/desiccations impacts } \\
\text { - } \quad \text { Overstocking } \\
\text { - } \quad \text { Veldt fires } \\
\text { - } \quad \text { Sloping land surface with rocky outcrops leads } \\
\text { to more erosion. } \\
\text { - Developments - tree cutting, ploughing along } \\
\text { slopes, promotion of bare surfaces, firewood } \\
\text { over-harvesting. } \\
\text { Drought impacts } \\
\text { - } \quad \text { Lack of food (hunger) } \\
\text { - } \quad \text { Livestock mortalities (lack of forage) } \\
\text { - } \quad \text { Diseases and malnutrition prevalence. } \\
\text { - } \quad \text { Lack of rains hence livelihood base. }\end{array}$ \\
\hline $\begin{array}{l}\text { Chobe and } \\
\text { North East }\end{array}$ & Unreliable rainfall & $\begin{array}{l}\text { Food and forage insecurity- climate change as } \\
\text { stressor, leads to poor grazing conditions, low food } \\
\text { production, degradation and drought. } \\
\text { Water insecurity - water demands not met- thus } \\
\text { water scarcity results as well as dams drying out. } \\
\text { Biodiversity challenges: Animals die of thirst, } \\
\text { diseases and hunger prevalence, loss of seed banks } \\
\text { (traditional seeds), extinctions of certain veldt } \\
\text { products e.g. hard to find and some animals migrate } \\
\text { elsewhere, extinctions of certain veldt products e.g. } \\
\text { hard to find and some animals migrate elsewhere, } \\
\text { extinctions of certain veldt products e.g. they are } \\
\text { hard to find and some animals emigrate/relocate } \\
\text { elsewhere. } \\
\text { High government expenditure- more spending on } \\
\text { safety nets for people during dry years, } \\
\text { development is stalled. Human mortalities occur, } \\
\text { malnutrition in children may result in death } \\
\text { (children are the most vulnerable to malnutrition), } \\
\text { as well as the elderly. Salaries adjustment/increases } \\
\text { no longer possible as government is burdened with } \\
\text { poverty alleviation. Government and other } \\
\text { Departments scale down to meet food shortages. }\end{array}$ \\
\hline $\begin{array}{l}\text { North West } \\
\text { District }\end{array}$ & i. Climate change & $\begin{array}{l}\text { Climate change impacts: natural disasters (e.g. } \\
\text { droughts, floods); increase in diseases - human and }\end{array}$ \\
\hline
\end{tabular}


Atlhopheng J.R. (2019). Bots. J. Agric. Appl. Sci. 13 (Issue 2 - Special): 24-31. ISSN 2661-9008

\begin{tabular}{|l|l|l|l|}
\hline (Ngamiland) & ii. Water shortage & $\begin{array}{l}\text { wildlife; brings down national economy e.g. low } \\
\text { yields; escalates land degradation; riles conflicts } \\
\text { over natural resources. } \\
\text { Water shortage impacts: increase in diseases or } \\
\text { illnesses; stalled developments/economic } \\
\text { regressions; poor food access/nutrition; reduced } \\
\text { arable farming; land's aesthetic beauty declines; } \\
\text { animals/fauna suffer. }\end{array}$ \\
\hline $\begin{array}{l}\text { Kgalagadi, } \\
\text { Ghanzi, } \\
\text { Kweneng, } \\
\text { Southern, } \\
\text { South East }\end{array}$ & i. $\quad \begin{array}{l}\text { Climatic conditions (harsh } \\
\text { weather conditions) }\end{array}$ & $\begin{array}{l}\text { Impacts of harsh climatic/weather conditions): } \\
\text { food shortages, more floods e.g. } \text { Cyclone Dineo, } \\
\text { earthquakes, desiccations, more diseases and pests, } \\
\text { vegetation die-backs and emergence of unfamiliar } \\
\text { species, veldt fires. } \\
\text { Unreliable rainfall impacts: declines in crop } \\
\text { yields/harvests, shortage of thatch grass and for } \\
\text { grazing, escalation of poverty, more water scarcity. }\end{array}$ \\
\hline
\end{tabular}

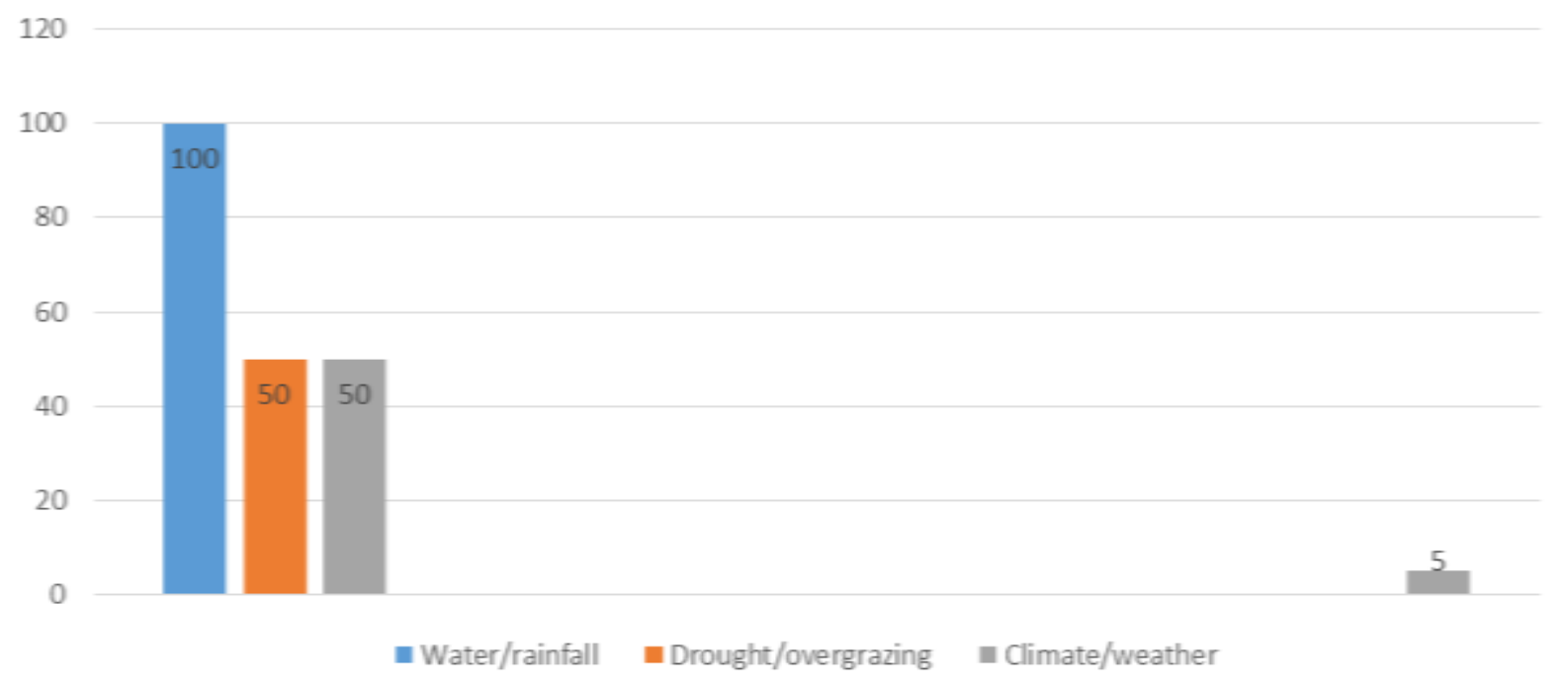

Fig. 2: Key challenges for biodiversity in Botswana (expressed in \%)

From the challenges indicated across the country, water shortage and rainfall deficiencies affect all the districts; while drought/overgrazing and climate/weather conditions are indicated in half of the district groups (Table 3), when assessing for the top five issues.

\section{The Mahalapye sub-district level impacts}

The biodiversity declines are characterized by fauna and flora (natural resources) being on the wane. This leads to reduced ecosystem services (as livelihood resources). Poverty, crime (e.g. theft for survival), and lack of peace ensure, hence a life of anxieties for the communities.

The land degradation challenges are due to desiccations which manifest through reduced hence insufficient range resources and loss of habitats. The other causes of land degradation include overharvesting of veldt products, harvesting of medicinal plants, human utilization means trees/vegetation are affected, elephant tree damages, modern infrastructure changes natural environment, too much wildlife in one area as well as livestock overstocking (e.g. cattle trails, elephants on trees), veldt fires, bare soil leading to erosion.

With climate change, the path of progression is that: climate change $\rightarrow$ droughts $\rightarrow$ desertification. Impacts include poor rains, excessive heat, malnutrition \& hunger, uncontrolled birth rates (people tend to have more babies during droughts - it is perceived), high livestock mortality and onset of dry windy conditions.

The implications for sustainable development 


\section{The 'good' about Botswana}

Botswana districts have natural resources, as the basis for calling their country 'good'. The natural resources offer livelihood choices through ecosystem services. There are social as well as economic benefits - that relate to the diverse biodiversity.

Specifically, the biodiversity provides social values such as natural beauty, as historical databanks for future generations to benefit from i.e. proffers inter-generational inheritance. The biodiversity is also intertwined with culture - hence culture values/norms relate to the biodiversity. Biodiversity offers protection. The livelihood is developed and diversified through biodiversity. With biodiversity are onset of applications of governance (on the natural resources) to ascertain its sustenance. The biodiversity benefits from the knowledge system (traditional), however, modern science has increasingly taken over.

The economic benefits, which enhance sustainable development include income generation, tourism and equitable income generation from the proceeds arising from natural resources. This may allude to the community based natural resources management (CBNRM) principles. Various venture investments are highlighted in some districts e.g. the Ngamiland (tourism hub).

\section{The challenges - what is 'bad' about Botswana}

There are widespread water shortages, hence the country experiences water security as a threat to sustainable development. These limit sustainable development endeavours e.g. onset of diseases/illnesses for people as well as for wildlife and livestock - hence attacking livelihood securities. Water is a key stressor for sustainable development in the districts assessed. This affects not only health and wellbeing, but leads to food insecurity for people and various fauna e.g. limited range resources including grazing which lead to overgrazing as the droughts intensify in the arid realm. Botswana thus manifests droughts and land degradation as a result of water and rainfall shortages. Batswana term the water shortages/limited rainfall as manifesting harsh climatic/weather conditions - which they attribute to climate change impacts. The result is onset of disasters in Botswana, as the droughts escalate, vegetation die-backs increase and the emergence of unfamiliar species -hence a change in the ecology as the traditional knowledge systems may relate to it. Other disasters relate to escalation in veldt fires, further denuding the forage/cover that may remain. In essence, the water scarcity and limited rains (emanating from climate change) degrade the nation to a state of extensive poverty, as their biodiversity livelihood base is eroded/lost.

\section{Conclusions}

The study set out to investigate what is perceived to be 'good' about Botswana, and whether biodiversity issues emerge from district perception audits. It has been concluded that, about $20 \%$ accounts for biodiversity being perceived as contributing to the 'good' of Botswana. It is mostly social values that dominate the minds of citizens, when they reflect on what is good about their country. When biodiversity benefits are broken into the social and economic benefits, most benefits are perceived to be social -yet again. The natural beauty of the land (biodiversity), its protective value and its ability to store data for future generations; as well as being culture and inheritance reassurances outweigh the indicated economic benefits which hinge on income generation, tourism and investments.

The challenges to biodiversity, mainly arise from climate/weather related impacts. The widespread water shortages arising from limited rainfalls under climate change, lead to a myriad of challenges. There is water insecurity with consequent food insecurity - for man and beast. There is vegetation die backs and mortalities on livestock, wildlife - hence eroding the base for livelihood safety nets. The loss of habitats and change in vegetation status (emergence of new unfamiliar species) and land degradation, further erode the biodiversity base, hence the ecosystem services. There is thus, onset of poverty and disasters such as droughts and veldt fires.

Thus sustainable development challenges as highlighted in the National Development Plan 11 and the Vision 2036 need to be pursued with zeal. The national initiatives need to be communicated better, with simplified messages that aim to empower local communities into sustainable development actions, where their traditional knowledge systems are built upon i.e. used as part of sustainable solutions. These may be applied to the indicators and targets developed for SDGs, NDP11 and Vision 2036 for targeted interventions. Some of the main gaps include silo planning i.e. that there is poor understanding of ecosystem services contribution to the national economy - a major gap that needs to be filled. Policymakers, planners and financiers need to include the ecosystem services in their analysis for sustainable solutions e.g. plans, projects for development and in sustainable land management.

\section{Acknowledgments}

The Government of Botswana and the United Nations Environment Programme are thanked for the co-sponsorship of the National Action Programme (NAP), especially the biodiversity/climate change interactions. The dissemination efforts are important 
in advocacy and awareness, to fill the gap in knowledge related to the value of biodiversity in national economy and sustainable development.

\section{References}

Ashkenazy Y., Yizhaq H. and Tsoar H. (2012) Sand dune mobility under climate change in the Kalahari and Australian deserts. Climatic Change June 112(3-4): 901-923.

Botswana Intended Nationally Determined Contribution (2016)

UNFCCC https://www4.unfccc.int/sites/ndcstaging/PublishedDo cuments/Botswana\%20First/BOTSWANA.pdf accessed March 11, 2019.

Cashdan E. (1986) Competition between Foragers and Food-Producers on the Botletli River, Botswana. Africa. Journal of the International African Institute 56(3):299-318.

Community Based Natural Resources Management Policy. Government Paper No. 2 of 2007. Ministry of Environment Wildlife and Tourism. Printed by The Botswana Government Printer, Gaborone, Botswana.

Cordova C.E, Scott L., Chase B.M. and Chevalier M. (2017) Late Pleistocene-Holocene vegetation and climate change in the Middle Kalahari, Lake Ngami, Botswana. Quaternary Science Reviews 1 September 171:199-215.

Hambira W.L. (2017) Botswana tourism operators' and policy makers' perceptions and responses to the tourism-climate change nexus - vulnerabilities and adaptations to climate change in Maun and Tshabong areas. Nordia Geographical Publications 46 No.2.

Keller K., von Maltitz G., Seeley M., Atlhopheng J. and Lindeque L. (2017) Sothern African Arid Lands: current status and future prospects. In: M.K. Gaur, V.R. Squires (eds.) Climate Variability Impacts on Land Use and Livelihoods in Drylands. Springer International Publishing AG 2018. Pages 243-260. DOI 10.1007/978-3-319-5668.1-8_12.

Mayaud J.R., Bailey R.M. and Wiggs G.F.S. (2017). A Coupled Vegetation/Sediment Transport Model for Dryland Environments. Journal of Geophysical Research: Earth Surface 122(4): 875-900.

National Biodiversity Strategy and Action Plan (2016). Department of Environmental Affairs, Gaborone, Botswana.

National Development Plan 11 - April 2017 - March 2023. Republic of Botswana.

Nyumba T.O., Wilson K., Derrick C. J., Mukherjee N. (2018) The use of focus group discussion methodology: Insights from two decades of application in conservation. Methods in ecology and evolution; Jan 9(1);20-32.

Reed M.S., Stringer L.C., Dougill A.J., Perkins J.S., Atlhopheng J.R., Mulale K., Favretto N. (2015). Reorienting land degradation towards sustainable land management: linking sustainable livelihoods with ecosystem services in rangeland systems. Journal of Environmental Management. March 151:472-85.
The Windhoek Declaration for Enhancing Resilience to Drought in Africa (2016). Windhoek, Namibia.

VISION 2036- Achieving Prosperity for All (2016). Republic of Botswana. Published by LENTSWE LA LESEDI (PTY) LTD. On behalf of - THE VISION 2036 PRESIDENTIAL TASK TEAM, GABORONE, BOTSWANA.

Yiran G. and Stringer L. (2017) Adaptation to Climatic Hazards in the Savannah Ecosystem: Improving Adaptation Policy and Action. Environmental Management 60(4):665-678. 